\title{
The Utilization Interactive Digital Media Comic In Indonesian Historical Learning to Support Independet Learning at SMA Al-Izzah
}

\section{Moch. Dimas Galuh Mahardika ${ }^{1}$, Nur Wahyu Putra ${ }^{2}$}

Universitas Sebelas Maret ${ }^{1}$

SMA Al-Izzah²

1dimas.dg20@gmail.com, ²wahyublog25@gmail.com

\section{Article History}

accepted 1/09/2020

approved 4/10/2020

published 1/12/2020

\begin{abstract}
The development of technology in the era of industrial revolution 4.0 has a comprehensive impact into aspects of life, one of which is in the learning of history. The use of electronic media for historical learning needs has begun to be encouraged in various schools. Conventional historical learning is usually still one-way, or in other words still teaching oriented. Thus with the development of technology and to meet the needs of the times, learning media needs to be used in order to improve the quality of learning. In addition, with the use of learning media, it is expected that students have an interest in participating more in historical learning. This research tries to review the use of digital comic learning media in the subjects of Indonesian History in class $X$ MIA 3 senior high school Al-Izzah Kota Batu. The research method used a descriptive qualitative method.
\end{abstract}

Keywords: Comics learning media, historical learning

\begin{abstract}
Abstrak
Perkembangan teknologi di era revolusi industri 4.0 memiliki dampak yang menyeluruh ke dalam aspek kehidupan, salah satunya di dalam pembelajaran sejarah. Pemanfaatan media elektronik untuk kebutuhan pembelajaran sejarah sudah mulai digalakkan di berbagai sekolah. Pembelajaran sejarah yang konvensional biasanya masih bersifat satu arah, atau dengan kata lain masih bersifat teaching oriented. Maka dengan berkembangnya teknologi dan untuk memenuhi kebutuhan zaman, media pembelajaran perlu untuk digunakan dalam rangka memperbaiki kualitas pembelajaran. Selain itu, dengan digunakannya media pembelajaran, diharapkan siswa memiliki ketertarikan untuk lebih banyak berpartisipasi dalam pembelajaran sejarah. Riset ini mencoba mengulas pemanfaatan media pembelajaran komik digital pada matapelajaran Sejarah Indonesia di kelas X-MIA 3 SMA Al-Izza Kota Batu. Metode penelitian yang digunakan pada riset ini adalah metode kualitatif deskriptif.
\end{abstract}

Kata Kunci: Media pembelajaran komik, pembelajaran sejarah

Social, Humanities, and Education Studies (SHEs): Conference Series https://jurnal.uns.ac.id/shes 


\section{PENDAHULUAN}

Pengajaran sejarah merupakan sebuah usaha untuk mengkaji masa lalu di dalam lingkungan pendidikan formal. Sejarah yang notabene adalah komunikasi antara masa depan dan masa lalu yang terus berkesinambungan, selalu menyimpan fakta-fakta menarik yang terpisah bagaikan puzzle (Carr 2018). Maka peristiwa sejarah adalah sebuah susunan dari fakta-fakta yang telah direkonstruksi dengan menggunakan perangkat metode yang akademis. Narasi sejarah yang dipelajari di sekolah adalah hasil dari rekonstruksi fakta-fakta dari peristiwa masa lalu yang dirangkai secara kronologis. Salah satu tujuan utama dari pembelajaran sejarah di sekolah adalah untuk memberikan kesadaran historis kepada siswa (Seixas 2004). Khusus untuk siswa SMA, sejarah diberikan dengan menggunakan pendekatan akademis. Artinya siswa sudah mulai diajarkan untuk menganalisis hubungan sebab-akibat, keberlanjutan, dan perubahan dari sebuah peristiwa sejarah.

Karakteristik pembelajaran sejarah yang ideal adalah dengan mengajarkan peristiwa sejarah kepada siswa secara kronologis berdasarkan pembabakan peristiwa sejarah. Unsur-unsur di dalam sejarah yang meliputi manusia, ruang, dan waktu disampaikan kepada siswa dan dipelajari sebagai salah satu konsep dasar yang harus mereka mengerti. Perspektif waktu meurpakan dimensi yang snagat penting, karena materi yang ada dalam pembelajaran sejarah harus dapat dikaitkan dengan persoalan masa kini dan masa depan. Sejarah pada hakikatnya adalah suatu peristiwa sejarah dan perkembangan masyarakat yang menyangkut berbagai aspek kehidupan seperti politik, ekonomi, sosial, budaya dan agama, sehingga pendekatan multidimensional perlu dilakukan dalam mempelajari sejarah. Pembelajaran sejarah adalah matapelajaran yang mengaji permasalahan dan perkembangan masyarakat dari masa lampau, masa kini baik di Indonesia maupun di luar Indonesia (Agung dan Wahyuni 2013).

Era revolusi industri 4.0 yang kerap digaungkan menengarai sebuah perubahan zaman yang cukup berdampak pada semua kini kehidupan. Perkembangan teknologi yang cukup pesat dan distribusi informasi yang begitu cepat menyeret manusia ke dalam sebuah kebiasaan baru, kemudahan akses membuat manusia tidak perlu repot untuk bergerak demi mendapatkan suatu informasi (Savitri 2019). Problem yang sering muncul di dalam pembelajaran sejarah adalah banyaknya materi yang harus dipelajari siswa dan metode pengajaran yang masih bersifat konvensional membuat sejarah terlihat tidak menarik di depan siswa. Maka dari itu diperlukan sebuah susunan kegiatan pembelajaran yang menarik untuk kemudian dapat dijadikan landasan dalam memperbaiki kualitas pembelajaran sejarah (Kitson 2011). Perkembangan teknologi yang cukup pesat juga menguntungkan bagi guru karena teknologi dapat dimanfaatkan di dalam pembelajaran sejarah, atau boleh diistilahkan sebagai modernisasi pembelajaran sejarah. Salah satu di antaranya adalah pemanfaatan media elektronik dalam pembelajaran sejarah.

Media berasal dari bahasa latin, yang merupakan bentuk jamak dari kata medium. Medium secara harfiah dapat diartikan sebagai pengantar atau perantara. Malik mengungkapkan bahwa media pembelajaran merupakan segala sesuatu yang dapat digunakan untuk menyalurkan pesan, sehingga dapat merangsang minat, pikiran, perhatian dan perhatian peserta didik dalam kegiatan pembelajaran untuk mencapai tujuan pembelajaran tertentu (Sumiharsono dan Hasanah 2017). Media pembelajaran dapat diartikan sebagai alat komunikasi yang berfungsi sebagai pengantar pesan (pelajaran) kepada siswa untuk mencapai tujuan pembelajaran.

Penggunaan media pembelajaran yang sesuai dapat dengan materi pembelajaran dapat memberikan dampak yang baik berupa hasil belajar dan aktivitas siswa dalam 
belajar. Media merupakan bagian integral dalam komponen pembelajaran, dengan adanya media penyampaian pembelajaran jadi lebih menarik dan interaktif (Satrianawati 2018, 19). Peningkatan hasil belajar merupakan indikasi atas ketercapaian tujuan pembelajaran, maka dapat disimpulkan bahwa penggunaan media pembelajaran dapat membantu siswa untuk mencapai atau menuntaskan tujuan pembelajaran.

Media pendidikan atau media intruksional memberikan penekanan pada aspek pendidikan yang dituju oleh media, yang dapat pula digunakan untuk keperluan hiburan, penyampaian informasi dan kegiatan pengajaran. Media instruksional pertam pad era modern adalah hasil percetakan. Buku teks diterima secara universal sebagai bagian pendidikan. Memberikan sumbangan pada pengajaran dan kesempatan belajar yang lebih luas pada umat manusia (Schramm 1977). Manusia pada saat ini sudah memasuki era post-print culture, membawa manusia pada budaya percetakan. Ide dan gagasan tersebar luas melalui buku dan kertas-setidaknya di awal abad XX (Daniels 1981). Perkembangan tersebut semakin mengalami kemajuan sejak munculnya media elektronik. Awalnya media-media tersebut tidak ditujukan secara khusus untuk kebutuhan pembelajaran. Prinsip yang digunakan media-media tersebut tetaplah sama yakni sebagai penyampai pesan, dengan demikian media instruksional atau media pembelajaran adalah faktor tambahan bagi guru dalam proses belajar mengajar (Schramm 1977; Kee 2014). Penggunaan media, khususnya media visual dalam proses pembelajaran dapat dilakukan termasuk dalam pembelajaran sejarah.

Media pembelajaran ini pernah dikembangkan oleh Putra (2019) dengan judul riset "Pengembangan Media Historical-Komik Interaktif (HI-MITA) pada Materi Kedatangan Bangsa Eropa di Nusantara Untuk Meningkatkan Hasil Belajar Siswa Kelas X Perbankan SMKN 2 Boyolangu". Hasil uji coba efektivitas media pada kelompok kecil memperoleh skor post-test sebesar $91.6 \%$ dengan kriteria sangat efektif. Hasil riset uji coba kepraktisan kelompok kecil diperoleh skor sebesar 92\% dengan kriteria praktis. Berdasarkan data tersebut media Hi-Mita dinilai efektif dalam meningkatkan hasil belajar siswa serta praktis penggunaannya dalam kegiatan belajar mengajar dalam skala kelompok kecil. Setelah melalui uji coba kelompok kecil, media harus melalui uji coba kelompok besar.

Pada uji coba kelompok besar dilakukan uji efektivitas dan uji kepraktisan terhadap media sama seperti pada saat uji coba kelompok kecil. Pada uji coba efektivitas kelompok besar diperoleh hasil skor post-test sebesar $89.6 \%$ dengan kriteria sangat efektif. Pada uji coba kepraktisan kelompok besar diperoleh skor sebesar $91.1 \%$ dengan kriteria praktis. Berdasarkan data tersebut media Hi-Mita dinilai efektif dalam meningkatkan hasil belajar siswa serta praktis penggunaannya dalam kegiatan belajar mengajar.

Riset ini dilaksanakan di SMA Al-Izzah Kota Batu, sebuah sekolah yang di dalamnya terdapat pondok pesantren, dan sekolah ini termasuk salah satu sekolah favorit di Kota Batu. Bapak Nur Wahyu Putra selaku guru matapelajaran sejarah, berkolaborasi dengan peneliti dalam riset ini. Kelas X-MIA 3 adalah subjek riset ini, peneliti akan mengamati pemanfaatan media pembelajaran komik digital yang digunakan dalam matapelajaran sejarah Indoenesia. Perlu diketahui, di sekolah ini tidak menggunakan pembelajaran daring, mengingat di sekolah ini siswa dilarang untuk menggunakan gadget. Pembelajaran di SMA Al-Izzah Kota Batu menggunakan pembelajaran luring. Meskipun demikian, para guru dan siswa tetap mematuhi protokol kesehatan yang berlaku pada saat beraktifitas di dalam lingkungan sekolah.

Artikel ini ditulis dengan tujuan untuk memaparkan kondisi pembelajaran di kelas X-MIA 3 SMA Al-Izzah Kota Batu dengan memanfaatkan media pembelajaran komik digital interaktif dalam menunjang aktifitas belajar mandiri siswa. Selain itu, artikel ini dapat dijadikan referensi baru untuk para pengajar sejarah, khususnya di SMA sebagai penambahan perspektif untuk perbaikan kulaitas pembelajaran sejarah 


\section{METODE}

Penelitian kualitatif di dalam pembelajaran merupakan kegiatan pengumpulan, analisis, dan interpretasi data naratif dan visual secara komperhensif untuk mendapatkan wawasan tentang potensi sebuah fenomena pembelajaran (Mills dan Gay 2016). Penelitian ini bertujuan untuk mengetahui fenomena yang terjadi dalam kondisi alamiah, bukan dengan perlakuan khusus, maupun eksperimental. Subjek yang diamati pada penelitian ini adalah aktifitas siswa kela X-MIA 3 dalam pembelajaran sejarah dengan menggunakan media pembelajaran komik digital dalam rangka menunjang aktifitas belajar mandiri. Peneliti dan guru saling berkolaborasi dalam penelitian ini sehingga data lapangan yang didapatkan dapat bersfiat objektif. Beberapa alat yang digunakan dalam penelitian ini di antaranya lembar catatan lapangan yang berfungsi untuk merekam segala aktifitas dalam kegiatan pembelajaran, dan studi dokumentasi.

\section{Media Pembelajaran Komik}

\section{HASIL DAN PEMBAHASAN}

Komik merupakan rangkaian gambar-gambar yang diletakan secara berurutan dan membentuk sebuah alur cerita atau informasi. Komik berasal dari kata "comic" yang berarti segala sesuatu yang lucu yang bersifat menghibur. Berdasarkan pernyataan tersebut maka dapat dikatakan bahwa komik sejatinya digunakan untuk tujuan entertainment. Komik dibuat dengan tujuan untuk menghibur pembacanya. Komik merupakan gambar-gambar serta lambang lain yang terjuktaposisi (posisi berdekatan) dalam urutan tertentu untuk menyampaikan suatu informasi atau mencapai tanggapan estetis dari pembacanya (McCloud 2002).

Maharsi (2014) mendefinisikan komik sebagai gambar dan kata untuk menceritakan atau mendramatisir suatu ide. Komik juga dapat diartika sebagai medium yang bercerita atau berekspresi dengan bahasa dan gambar yang tersusun (Darmawan 2012). Definisi tentang komik tersebut sejatinya memiliki satu prinsip yang menyatakan bahwa komik merupakan ide, gagasan, peristiwa yang direkontruksikan dalam bentuk visual (gambar).

Interaktif memiliki arti saling berinteraksi atau antarhubungan yang salin akitif. Perangkat pembelajaran interaktif dapat dimaknai sebagai perangkat yang bersifat aktif didesain untuk dapat melakukan perintah balik kepada pengguna untuk melakukan aktivitas (Prastowo 2015). Komik interaktif merupakan perangkat/media pembelajaran yang didesain untuk terjadinya interaksi antara siswa dengan 'tokoh' yang ada di dalam komik tersebut.

Komik interaktif dibuat berbasis digital (dapat diakses oleh komputer dan smartphone). Kemajuan komputer atau perangkat digital lainnya memungkinkan terjadinya interaksi dengan individu, menyimpan dan mengolah sejumlah informasi, dan menjadikan komputer sebagai media yang dominan dalam bidang pembelajaran (Prastowo 2015). Berdasarkan hal tersebut maka komik interaktif dibuat menggunakan format digital sehingga memungkinkan adanya interaksi antara individu dengan media pembelajaran secara efektif dan komunikatif.

Penggunaan media visual pada pembelajaran sejarah dapat mengintegrasikan antara kata dan gambar menghasilkan bahasa visual yang kuat di ingatan. Pengembangan dan penyususnan media visual dapat membantu siswa untuk menggali gagasan, menonjolkan gagasan pentimg, memahami peristiwa, meningkatkan keterampilan dan strategi memahami bacaan, serta memudahkan dalam mempertahankan ingatan. Sejatinya pola penggunaan sarana visual dalam menyampaikan gagasan telah menjadi karakteristik manusia sejak zaman dahulu kala, hal tersebut dibuktikan dengan lukisan-lukisan di dinding gua yang mengekspresikan ide. Penggunaan 2000 bentuk piktograf pada kebudayaan Sumeria 4000 SM dan 
hieroglif bangsa Mesir menunjukan bahwa pewarisan ilmu pengetahuan/gagasan dapat dilakukan melalui media gambar. Penggunaan gambar ini pula dapat dilakukan dalam proses pembelajaran contohnya penggunaan komik sebagai media pembelajaran. Penggunaan gambar di kelas dapat memperkaya lingkungan pembelajaran (Margulies dan Valenza 2008).

Sejarah ditulis berdasarkan fakta dan sumber yang valid supaya rekonstruksi peristiwa yang dinarasikan dapat bersifat objektif. Sejarah dapat memantik daya imajinatif tentang pengalaman yang kemudian disampaikannya kepada pembaca. Sejarah sangat serupa dengan karya sastra novel, karena keduanya mengisahkan sebuah cerita. Perbedaan utama berada pada rekontruksi imajinatif atas fakta dan karakter di dalamnya (Daniels 1981). Sejarah merupakan cerita atas masa lalu dan untuk menyampaikannya bisa melalui berbagai media visual seperti komik. Adapun storyboard dari komik digital yang digunakan dalam riset ini sebagai berikut.

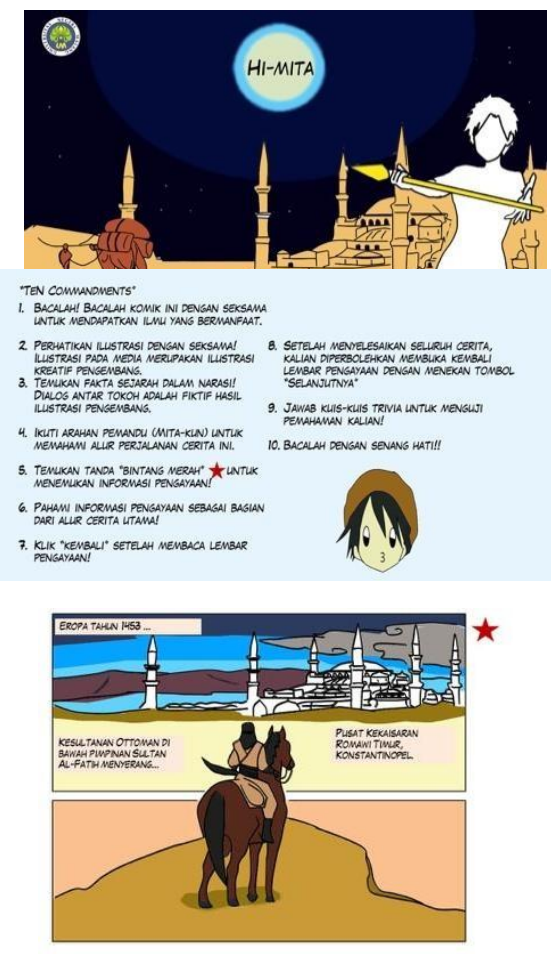

Sampul Pembuka

Petunjuk Penggunaan

Cerita Pembuka

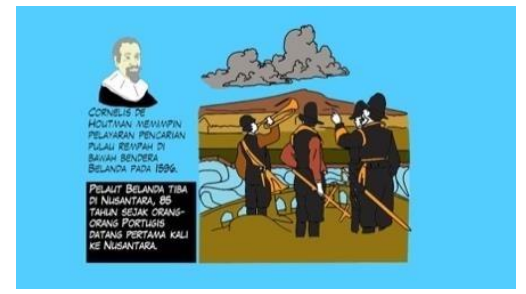

Inti Cerita

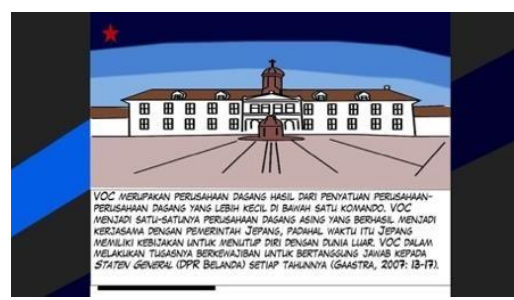

Halaman Pengayaan 


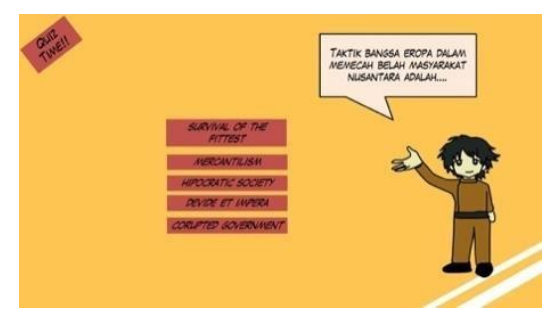

Kuis Interaktif

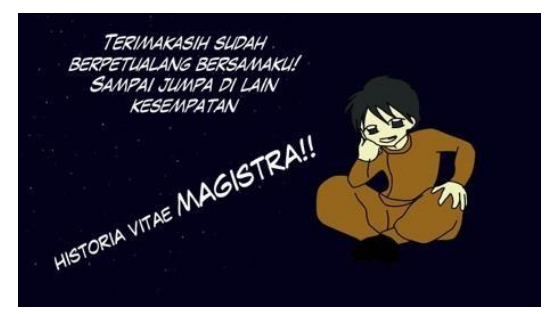

Halaman Penutup

\section{Pembelajaran Sejarah dengan Menggunakan Komik Digital Interaktif}

Fokus utama matapelajaran sejarah di tingkat sekolah menengah atas adalah tahap kelahiran peradaban manusia, evolusi sistem sosial dan perkembangan kebudayaan dan ilmu pengetahuan. Sasaran utama pembelajaran sejarah adalah meningkatkan pemahaman terhadap proses perubahan dan perkembangan yang dilalui umat manusia hingga mampu mencapai perkembnagan yang sekarang ini. Meningkatkan pemahaman terhadap akar peradaban dan penghargaan terhadap kesatuan dasar manusia, menghargai berbagai sumbangan yang diberikan oleh semua kebudayaan pada peradaban manusia secara keseluruhan. Memperkokoh pemahaman interaksi saling menguntungkan antarberbagai kebudayaan merupakan faktor yang penting dalam kemajuan kehidupan manusia. Memberikan kemudahan pada siswa yang berminat mempelajari sejarah suatu negara dalam kaitannya dengan sejarah umat manusia secara keseluruhan (Kochhar 2008). Seiring dengan perkembangan teknologi dan untuk memenuhi tuntutan zaman, maka inovasi dalam pembelajaran sejarah mulai dilakukan, salah satunya adalah dengan pemanfaatan media pembelajaran.

Media pembelajaran digunakan sesuai dengan kebutuhan pembelajaran, media dapat digunakan pada kegiatan apersepsi, kegiatan inti, atau pada kegiatan penutup. Kegiatan pembelajaran dengan memanfaatkan media eletronik akan memberikan banyak dampak yang positif kepada siswa, pertama mereka akan lebih tertarik dan termotivasi dalam mengikuti kegiatan pembelajaran, kedua teknologi yang berkembang saat ini sudah berada di tangan siswa. Gadget atau smartphone yang dimiliki oleh siswa dapat dimanfaatkan untuk mengakses berbagai informasi yang dapat menunjang aktifitas belajar siswa (Kelly 2013). Mereka dapat berusaha menemukan sendiri informasi yang mereka butuhkan, sehingga kiat yang mereka lakukan akan dapat mengarahkan nalarnya untuk menganalisis informasi yang telah didapatkan.

Pemanfaatan media pembelajaran komik digital dilakukan di dalam kegiatan pembelajaran sejarah oleh Bapak Nur Wahyu Putra selaku guru SMA Al-Izzah sebagai salah satu bentuk penunjang untuk mendorong siswa belajar lebih mandiri. Pada kegiatan apersepsi, seperti biasa guru mengucapkan salam dan memanjatkan doa serta untuk mengantarkan siswa dalam mengawali kegiatan pembelajaran, guru memberikan beberapa pertanyaan kepada siswa terkait materi-materi yang diajarkan pada pertemuan sebelumnya. Pertanyaan yang diajukan merupakan pertanyaan-pertanyaan 
dasar yang menunjukkan indikator-indikator pemahaman siswa terhadap materi yang telah diajarkan, sekaligus menjadi acuan kesiapan siswa terhadap materi yang akan diajarkan.

Siswa terlihat cukup partisipatif ketika guru memberikan pertanyaan-pertanyaan tingkat dasar kepada siswa, beberapa dari mereka terlihat aktif untuk menjawab pertanyaan dari guru. Selanjutnya guru juga menjelaskan tujuan pembelajaran sesuai dengan K.D 3.1 tentang koloniaisme bangsa Eropa di Nusantara, sebenarnya materi ini diajarkan di kelas XI. Akan tetapi di kelas XI nanti siswa difokuskan untuk mengerjakan projek pengganti UN dan fokus pada hafalan Al-Qur'an, sehingga materi ini diberikan di kelas $X$. Materi pengantar untuk mengawali pembelajaran, guru memberikan penjelasan tentang awal mula abad renaissance yang menjadi cikal bakal era penjelajahan samudera hingga melahirkan masa penjajahan di nusantara. Setelah memberikan materi awal, siswa ditunjukkan media pembelajaran berupa komik dalam slide persentasi yang menggambarkan panel-panel peristiwa sejarah. Kemudian sebagai pengantar instruksional teknis dalam menggunakan media pembelajaran, guru memberikan penjelasan tentang panel-panel yang berisi materi inti pada media pembelajaran yang akan digunakan.

Masuk pada kegiatan inti, guru menampilkan media pembelajaran komik digital dengan menggunakan LCD. Sebenarnya media pembelajaran ini dapat diakses dengan menggunakan smartphone, akan tetapi sesuai dengan peraturan di sekolah ini siswa tidak diperbolehkan membawa smartphone sehingga guru harus menampilkan media di depan kelas dan siswa mengamati secara bersama-sama. Siswa nampak antusias dalam mengamati panel-panel komik, itu terlihat dari beberapa siswa yang sampai maju ke depan untuk mengamati panel-panel komik sejarah tersebut dengan lebih jelas. Lihat foto berikut.

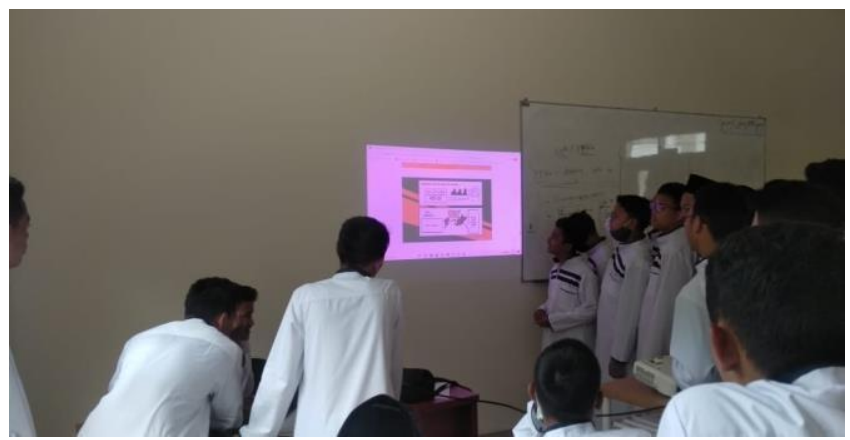

\section{Gambar 1. Siswa Mengamati Materi Yang Disajikan Melalui Media Pembelajaran Komik Digital Interaktif}

Proses pengamatan yang dilakukan oleh siswa tetap mendapatkan pendampingan dari guru. Siswa dapat mengajukan pertanyaan kepada guru ketika ada hal-hal yang tidak mereka mengerti dari materi yang tersaji di dalam media pembelajaran, dan pada posisi inilah guru berperan untuk memberikan penjelasan. Artinya dengan memanfaatkan media pembelajaran komik digital ini, siswa lebih aktif untuk berpartisipasi sehingga guru tidak perlu terlalu mendominasi dalam kegiatan pembelajaran. Guru memberikan arahan untuk menganalisis materi dan menginstruksikan siswa untuk mencatat beberapa poin yang dianggap penting penting. Setelah menganalisis materi, siswa diminta untuk memaparkan hasil analisisnya dalam bentuk penyampaian lisan di depan kelas. Siswa lain diperkenankan untuk memberikan tanggapan atas materi yang dipresentasikan. 
Pada kegiatan evaluasi, siswa diberikan tugas untuk mengerjakan soal untuk mengukur tingkat pemahaman siswa. Perolehan nilai siswa dapat dilihat pada tabel berikut. Kegiatan peunutp diisi oleh guru dengan memberikan penguatan atas materi yang telah dipelajari. Hal itu dilakukan untuk mengantisipasi apabila terjadi miskonsepsi ketika siswa belajar secara mandiri. Beberapa pertanyaan juga diajukan kepada siswa untuk melihat seberapa jauh pemahaman siswa. Daftar nilai siswa dapat dilihat pada tabel berikut.

Tabel 1. Nilai siswa setelah pemanfaatan media pembelajaran komik digital interaktif

\begin{tabular}{lll}
\hline No & Nama Siswa & Nilai \\
\hline $\mathbf{1}$ & A. Hisyam Ahmad Al-Kautsar Ichsan & 88 \\
$\mathbf{2}$ & A. Muh. Asyam Naufal Rizqi & 90 \\
$\mathbf{3}$ & Abdul Aziz Al-Hakim Yusuf & 92 \\
$\mathbf{4}$ & Abid Ghaisan Putra Kadarsan & 94 \\
$\mathbf{5}$ & Ahmad Mafaza Afnani & 96 \\
$\mathbf{6}$ & Akhdan Surya Khairizza & 90 \\
$\mathbf{7}$ & Arif Zanjabil Haq & 92 \\
$\mathbf{8}$ & Faiq Amrul Hakim & 96 \\
$\mathbf{9}$ & Faiq Amirul Hakim & 94 \\
$\mathbf{1 0}$ & Ghiffari Muhammad Addausi & 98 \\
$\mathbf{1 1}$ & Habil Ibra Wahyudi & 100 \\
$\mathbf{1 2}$ & Ihsan Dianta & 84 \\
$\mathbf{1 3}$ & Kenzie Raihan Al Thaf & 90 \\
$\mathbf{1 4}$ & Maulana Arvin Asshofi & 80 \\
$\mathbf{1 5}$ & Maulana Majid Albani & 100 \\
$\mathbf{1 6}$ & Migdad Aminuddin & 82 \\
$\mathbf{1 7}$ & Mohammad Fauzan Siddiq & 84 \\
$\mathbf{1 8}$ & Muhammad Altaf Alianto & 94 \\
$\mathbf{1 9}$ & Muhammad Firman Syafaat & 82 \\
$\mathbf{2 0}$ & Muhammad Gibran Adyatama Rachman & 86 \\
$\mathbf{2 1}$ & Muhammad Nazrey Zaidan Rafif & 86 \\
$\mathbf{2 2}$ & Najamudin Faizul Hadi & 94 \\
$\mathbf{2 3}$ & Raidtya Tanayadyaksa Setyanto & 78 \\
$\mathbf{2 4}$ & Raditya Yusuf Annafi' & 94 \\
$\mathbf{2 5}$ & Rafi Akbar Maulana & 88 \\
$\mathbf{2 6}$ & Sayyid Afif Al Hakim & 96 \\
$\mathbf{2 7}$ & Wan Muhammad Daffa Rafii Affandy & 98 \\
$\mathbf{2 8}$ & Yazid Farhan Mutaqqin & 88 \\
$\mathbf{2 9}$ & Zaidan Qaes Yamani & 94 \\
\hline & &
\end{tabular}

\section{SIMPULAN}

Orientsi pembelajaran yang dilaksanakan menggunakan pendekatan student oriented akan dapat tercapai dengan baik apabila sarana pembelajaran dapat dimanfaatkan secara maksimal. Pemanfaatan media dalam kegiatan pembelajaran sejarah akan memberikan dampak positif dalam rangka perbaikan kualitas pembelajaran. Aktifias belajar siswa akan disokong oleh media pembelajaran, sehingga guru tidak lagi menggunakan metode ceramah sepanjang pembelajaran. Siswa akan memiliki ketertarikan yang lebih besar terhadap pelajaran sejarah apabila mereka dihadapkan pada situasi belajar yang efektif dan menyenangkan. Dalam hal ini guru memang dituntut untuk selalu memberikan inovasi dalam mengajar, hal itu bertujuan untuk pengembangan kualitas pembelajaran dan kualitas mengajar guru secara personal. Maka dengan pengalaman-pengalaman belajar yang baru, guru dapat 
menemukan stimulan yang tepat bagi siswa, dan siswa dapat merasakan suasana belajar yang lebih berpihak kepada aktifitas belajar mereka.

\section{DAFTAR PUSTAKA}

Agung, Leo, dan Sri Wahyuni. 2013. Perencanaan Pembelajaran Sejarah. Ombak. Carr, E. H. 2018. What Is History? Penguin UK.

Daniels, Robert V. 1981. Studying History: How and Why? New Jersey: Precentice-Hall, Inc.

Darmawan, Hikmat. 2012. How to Make Comic. Yogyakarta: Plot Point Publishing.

Kee, Kevin. 2014. Pastplay: Teaching and Learning History with Technology. Ann Arbor: Univ. oif Michigan Press.

Kelly, T. Mills. 2013. Teaching History in The Digital Age. Digital humanities. Ann Arbor: The University of Michigan Press.

Kitson, Alison. 2011. Teaching and Learning History 11 - 18: Understanding the Past. Disunting oleh Chris Husbands. 1. publ. Maidenhead: McGraw-Hill Open University Press.

Kochhar, S. K. 2008. Teaching of History. Grasindo.

Maharsi, Indria. 2014. Komik dari Wayang Beber sampai Komik Digital. Yogyakarta: Badan Penerbit ISI.

Margulies, Nancy, dan Christine Valenza. 2008. Pemikiran Visual Alat untuk Memetakan Ide. Jakarta: PT Indeks.

McCloud, Scott. 2002. Understanding Comics (Memahami Komik). Jakarta: Pustaka AlKautsar.

Mills, Geoffrey E., dan L. R. Gay. 2016. Educational Research: Competencies for Analysis and Applications. Eleventh edition. Boston: Pearson.

Prastowo, Andi. 2015. Panduan Kreatif Membuat Bahan Ajar Inovatif Menciptakan

Metode Pembelajaran yang Menarik dan Menyenangkan. Yogyakarta: Diva Press.

Putra, Nur Wahyu. 2019. "Pengembangan Media Historical-Komik Interaktif pada Materi

Kedatangan Bangsa Eropa di Nusantara Untuk Meningkatkan Hasil Belajar Siswa Kelas X Perbankan SMKN 2 Boyolangu." Malang: Jurusan Sejarah FIS UM.

Satrianawati. 2018. Media dan Sumber Belajar. Yogyakarta: Deepublish.

Savitri, Astrid. 2019. Revolusi Industri 4.0: Mengubah Tantangan Menjadi Peluang di Era Disrupsi 4.0. Yogyakarta: Genesis.

Schramm, Wilbur. 1977. Media Besar Media Kecil Alat dan Teknologi Untuk Pendidikan. Yogyakarta: FKIS IKIP Yogyakarta.

Seixas, Peter C., ed. 2004. Theorizing Historical Consciousness. Toronto; Buffalo: University of Toronto Press.

Sumiharsono, Rudy, dan Hisbiyatul Hasanah. 2017. Media Pembelajaran. Jember: Pustaka Abadi. 